\title{
Analytical Modelling of Elastic Interference Fit Joints for Functionally Graded Materials M.Belhaou $^{1}$, N.Laghzale ${ }^{2}$ \\ 1.Lamat Laboratory, Enset, Rabat, Morocco, Email : belhaou.meriem@gmail.com \\ 2. Lamat Laboratory, Enset, Rabat, Morocco, Email : n.laghzale@um5s.net.ma
}

\begin{abstract}
For a very long time, fretted assemblies have been made, in particular to provide wooden wheels with a more resistant running surface. Today, shrinking is an operation which consists in making a connection between two cylindrical parts with any material. In this paper, we're going to apply it for functionally graded materials. This work focuses on the analytical development of the residual stresses when the two assembled parts are circular cylinders and elastic deformation under plane strain condition. Both cylinders are made of functionally graded materials whose volume fractions are power functions of the radius. In order to simplify the calculations, we assume the Poisson's ration constant. We obtain the theoretical solutions by assuming a uniform strain field within the representative volume element and Von-mises criterion.
\end{abstract}

\section{Résumé}

Le frettage, également connu en anglais sous le nom de shrink fit, est un procède qui consiste à assembler deux pièces cylindrique par sertissage. Ce procédé est très utilisé dans le domaine industriel : en industrie automobile, aéronautique, ferroviaire, etc.

Ce travail de recherche s'intéresse à l'analyse analytique des contraintes résiduelles et particulièrement à la pression résiduelle de contact induite par le frettage dans le cas des matériaux à gradient fonctionnel. Les déplacements sont supposés produits par des déformations dans le domaine élastique dans l'arbre et/ou dans la roue.

Mots clefs : Matériaux à gradient fonctionnel, Frettage, Interférence, Contraintes résiduelles, Critère de l'écoulement Elastique.

Keywords : Functionally Graded Materials, Residual Stresses, Interference, Elastic deformation.

\section{Introduction}

The main advantage of Interference fit joint is to avoid the use of other additional parts, thus reducing manufacturing costs and it guarantees a long assembly life, good static and dynamic balancing. However, the studies which have been carried out so far [1-2] show that the equivalent residual stresses induced by this process increase with the increasing of the interference and residual contact pressure and can rapidly exceed the permissible stress of the coupling. And then they become a potential danger to the integrity of the assembly.

Functionally gradient material is an ingeniously advancedmaterial that is able to survive in a harsh workingenvironment, without losing its properties, and without failing during service. Their major advantage is that their physical properties vary gradually according to the composition or microstructure of the material. This gradation of properties leads to improved performance, namely heat transfer [3] and reduction of local stresses [4-5].

Although in the past the stresses and deformations generated by interference fits with homogenous materials, and the analyses of thick-walled pressure vessels made of functionally graded material have been studies. Combining both of them by analyzing the stresses and deformations generated by interference fits for functionally graded material still remains a subject of focus. This paper focuses on the effect of interference on the distribution of residual stress for FGM in elastic field. An analytical model of an axisymmetric interference fit composed by two cylinders under a plain strain condition and based on Von-mises criterion is developed. Both cylinders are made of functionally graded materials whose volume fractions are power functions of the radius. In order to simplify the calculations, we assume the Poisson's ration constant.

\section{Problem formulation}

\subsection{Geometry Characteristics}

We consider in our interference fit assembly: a hollow FGM shaft subjected to the action of internal and external pressure loadings, respectively Pi and Pc. And a FGM circular cylinder subjected to only external pressure loading Pc. Fig. 1 shows the characteristics of the joint geometry before assembly.

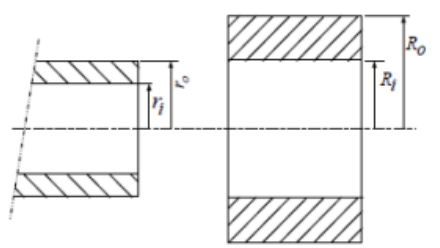

Fig1.Geometry of the joint before assembly

By assuming a cylindrical coordinate system $(r, \theta, z)$, we consider that the both cylinders consists of two idealized isotropic materials, respectively $\mathrm{A}, \mathrm{B}, \mathrm{C}$ and $\mathrm{D}$. The volume of fraction $\mathrm{c}(\mathrm{r}) \in[0,1]$ of material $\mathrm{A}$ is given by: 
$c(r)=\frac{E(r)-E_{2}}{E_{1}-E_{2}}$

The materials are assumed linearly elastic and isotropic and in the graded materials Young's modulus depends only on the radial direction while Poisson's ratio is assumed constant. The axisymmetric load conditions reduce the problem to find the radial displacement $u(r)$, the stress $\sigma_{r}, \sigma_{\theta}$ and $\sigma_{z}$. We confines our attention to the plane strain problem. We use Young's modulus in power law form. Therefore $\mathrm{E}(\mathrm{r})$ is given by for the hollow shaft (2.2) and for the cylinder (2.3):

$E_{s}(r)=E_{s}\left(\frac{r}{r o}\right)^{n s}$

$E_{c}(r)=E_{c}\left(\frac{r}{R o}\right)^{n c}$

\subsection{Elastic Analysis of the hollow shaft and cylinder}

2.2.1. Preliminary calculations:

The Navier's equation assumes the form:

$\left(\frac{\partial^{2} u}{\partial r^{2}}+\frac{1}{r} \frac{d u}{d r}-\frac{u}{r^{2}}\right)+\frac{1}{E(r)} \frac{d}{d r}\left(\frac{d E(r)}{d r}+\frac{v}{1-v} * \frac{u}{r}\right)=0$

By assumption (2.2-2.3), one finds that the Eq. (2.4) becomes:

$\frac{\partial^{2} u}{\partial r^{2}}+\frac{(1+n)}{r} \frac{d u}{d r}+\left(\frac{n v}{1-v}-1\right) \frac{u}{r^{2}}=0$

(2.5)

Whose solution is :

$u(r)=A_{1} r^{-\frac{n}{k}-\frac{k}{2}}+A_{2} r^{-\frac{n}{2}+\frac{k}{2}}$

Where $A_{i}$ integration constants and $k$ is given by:

$k=-\sqrt{n^{2}+4-\frac{4 n v}{1-v}}$

The stresses equations for both hollow shaft and the cylinder are given by:

$$
\begin{aligned}
& \sigma_{r}=\frac{E(r)}{(1+v)(1-2 v)}\left[v \frac{u_{r}}{r}+(1-v) \frac{d u}{d r}\right] \\
& \sigma_{\theta}=\frac{E(r)}{(1+v)(1-2 v)}\left[(1-v) \frac{u_{r}}{r}+v \frac{d u}{d r}\right] \\
& \sigma_{z}=\frac{E(r) v}{(1+v)(1-2 v)}\left[\frac{u_{r}}{r}+\frac{d u}{d r}\right]
\end{aligned}
$$

Substituting Eq. (2.4) into (2.8) -(2.10), we have:

For the hollow shaft:

$$
\sigma_{s r}(r)=r^{\frac{n s}{2}-1}\left[\begin{array}{c}
r^{-\frac{k}{2}}[(n s+k s)(v-1)+2 v] B_{1}+ \\
r^{\frac{k}{2}}[(n s-k s)(v-1)+2 v] B_{2}
\end{array}\right]
$$

$$
\sigma_{s \theta}(r)=-r^{\frac{n s}{2}-1}\left[\begin{array}{c}
r^{-\frac{k s}{2}}[(n s+k s) v+2(v-1)] B_{1} \\
+r^{\frac{k s}{2}}[(n s+k s) v+2(v-1)] B_{2}
\end{array}\right]
$$

$$
\sigma_{s z}(r)=-r^{\frac{n s}{2}-1}\left[\begin{array}{l}
r^{-\frac{k s}{2}}(n s+k s-2) v[(n s+k s)(v-1)] \\
+2 v B_{1} \\
+r^{\frac{k}{2}}[(n s-k s)(v-1)-2 v] B_{2}
\end{array}\right]
$$

Where $B_{i}=\frac{E_{s}}{r_{o} 2(1+v)(1-2 v)}, i=1,2$

Same for the cylinder except :

$$
k s=k c, B_{1}=B_{3}, B_{2}=B_{4}, n s=n c
$$

\subsubsection{Solution:}

By using the boundary conditions, we obtain the explicit solutions.

First, for the hollow shaft the stress controlled boundary conditions are:

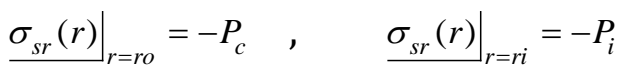

Then, for the cylinder the stress controlled boundary conditions are:

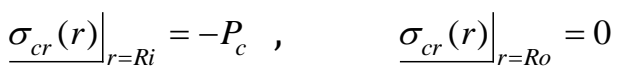

In the elastic field, the residual contact pressure is given by considering the radial displacement compatibility equation $\delta=u_{r c}-u_{r s}$ such that:

$$
P_{c}=\frac{\delta}{K}
$$

$\mathrm{K}$ is a constant which take into account the geometrical and mechanical characteristics of the joint for a plane strain case is given by:

$$
K=(1+v)(1-2 v)\left[\begin{array}{c}
\frac{R_{i}^{-\frac{n c}{2}+1} R_{o}^{n c}}{\left(Y_{c}^{\frac{k c}{2}}-Y_{c}^{-\frac{k c}{2}}\right) E_{c}}\left[\begin{array}{c}
\frac{Y_{c}^{-\frac{k c}{2}}}{[(n c-k c)(v-1)+2 v]} \\
\left.-\frac{Y_{c}^{+\frac{k c}{2}}}{[(n c+k c)(v-1)+2 v]}\right]
\end{array}\right] \\
\frac{r_{o}^{\frac{n s}{2}+1}}{\left(Y_{s}^{\frac{k s}{2}}-Y_{s}^{-\frac{k s}{2}}\right) E_{s}}\left[\begin{array}{c}
\frac{Y_{s}^{\frac{k s}{2}}}{[(n s-k s)(v-1)+2 v]} \\
\left.-\frac{Y_{c}^{-\frac{k s}{2}}}{[(n s+k s)(v-1)+2 v]}\right]
\end{array}\right]
\end{array}\right]
$$

In the following, we will determine the critical pressure $P_{e}$ at which material $\mathrm{B}$ in the hollow shaft begins to 
occur plastic deformation at the inner radius $\left(r=r_{o}\right.$ ).Substituting Eqs.(2.9)-(2.8) into the Von-Mises criterion, we have:

$$
\frac{\left.\underline{u}\right|_{r=r_{i}}}{r_{i}}-\left.\frac{d u}{d r}\right|_{r=r_{i}}=\frac{(1+v)}{E_{2}} * \frac{\sigma_{2}}{\sqrt{3}}
$$

We obtain then

$P_{e}=-\frac{\sigma_{2} E_{s}}{\sqrt{3} E_{2}} * \frac{\left(Y_{s}^{\frac{k s}{2}}-Y_{s}^{-\frac{k s}{2}}\right)}{n s * Y^{n s}} *$

1

$$
\left[\frac{Y_{s}^{\frac{k s}{2}}}{[(n s-k s)(v-1)+2 v]}-\frac{Y_{s}^{-\frac{k s}{2}}}{[(n s+k s)(v-1)+2 v]}\right]
$$

\section{Results and discussion}

Fig. 2 shows the distribution of the radial stress as a function of the radial position for different values of $n$ with an interference $\delta=0.02$ which corresponds to an elastic deformation of the shaft and the cylinder.

In $n=0$, the results show that stresses increase rapidly with increasing interference value resulting in maximum equivalent stresses located on the inner surface of the shaft. But in $\mathrm{n}=1$, the stresses don't which means that indeed the use of FGM's can lead to a reduction in stressors.

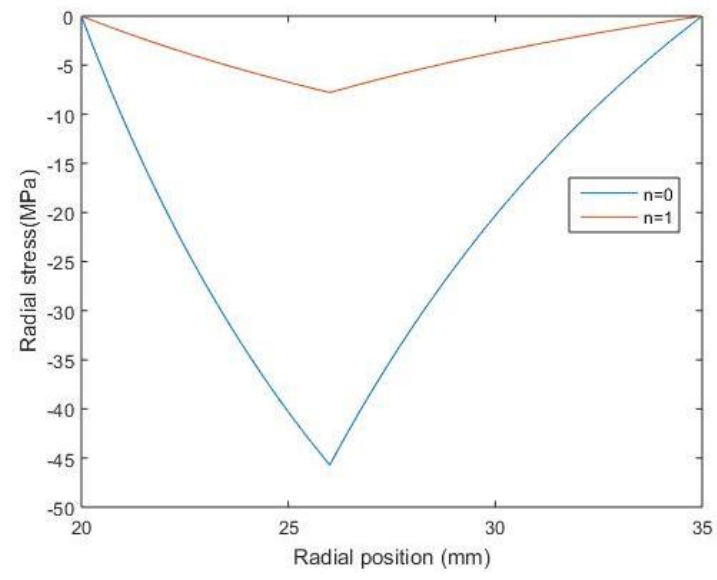

Fig 2.Distribution of radial stress

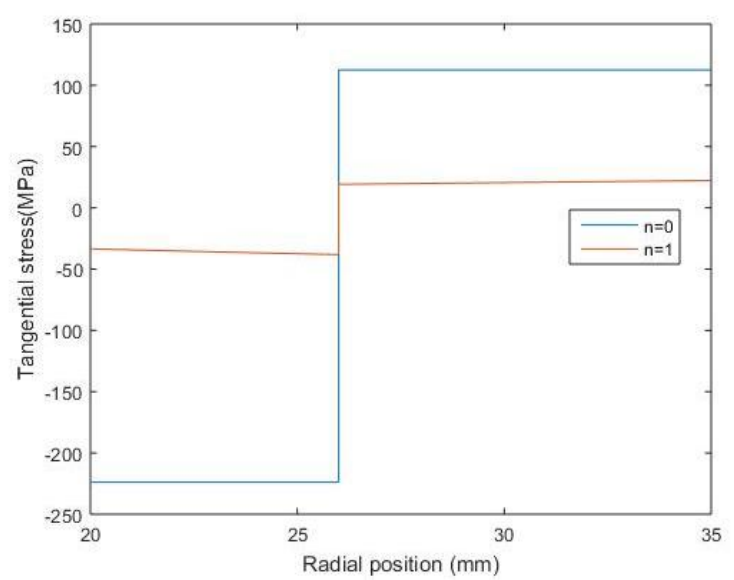

Fig 3.Distribution of tangential stress

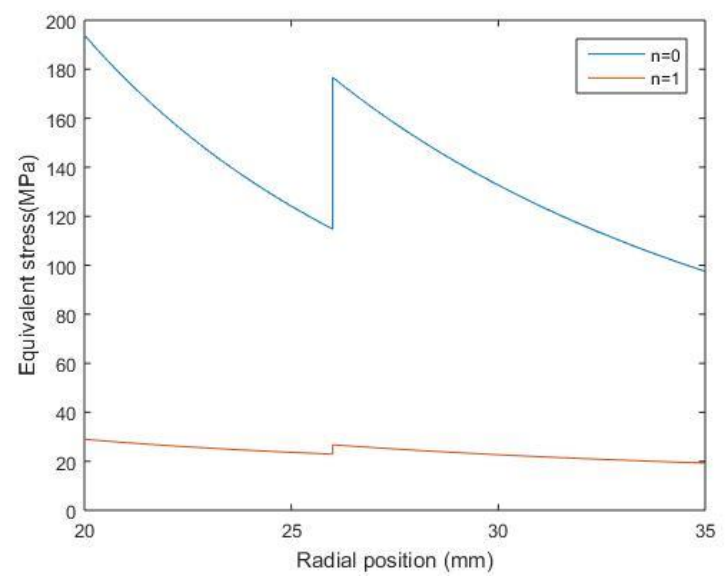

Fig 4.Distibution of equivalent stress

\section{Conclusion}

The AM developed in this paper deals with the distribution of residual stresses in an assembly formed by a hollow shaft and a cylinder. The assembly process is shrink-fit. Depending on the value of the interference, the deformations were simulated in the elastic range for both the shaft and the cylinder. The results show that the use of FGM's lead to reduction of local stresses and an improvement in the distribution of residual stresses.

\section{References :}

[1] Z. LABED and B. NECIB, Analyse des contraintes élasto-plastiques dans un cylindre sous l'effet de la variation de la pression interne, Sciences \& Technologie B - $\mathrm{N}^{\circ} 25$, Juin 2007, 65-70.

[2] N. Laghzale1, A. Bouzid, Analytical Modelling of Elastic-Plastic Interference Fit Joints, International Review on Modelling and Simulations (I.RE.MO.S.), Vol. 9, N. 3, ISSN 1974-9821 June 2016.

[3] Öchsner, A., Murch, G.E. et de Lemos, M.J.S. (2008),"Cellular and Porous Materials", WILEY-VCH, 398-417.

[4] Miyamoto, M., Kaysser, W.A., Rabin, B.H. et al. (1999), "Functionally Graded Materials Design". Processing and Applications.

[5] Suresh,S.,Mortensen, A (1998) Fundamentals of functionally Graded Materials, (IOM Communications Ltd,London). 